\title{
MODEL REGRESI DATA PANEL UNTUK MENGETAHUI FAKTOR YANG MEMPENGARUHI TINGKAT KEMISKINAN DI PULAU MADURA
}

\author{
Artanti Indrasetianingsih ${ }^{1 *}$, Tutik Khalimatul Wasik ${ }^{2}$ \\ ${ }^{1,2}$ Program Studi Statistika, Fakultas Matematika dan Ilmu Pengetahuan Alam, Universitas PGRI \\ Adi Buana Surabaya \\ *e-mail : Artanti.indra@gmail.com
}

\begin{abstract}
Poverty arises when a person or group of people is unable to meet the level of economic prosperity which is considered a minimum requirement of a certain standard of living or poverty is understood as a state of lack of money and goods to ensure survival. Panel data regression is the development of regression analysis which is a combination of time series data and cross section data. Panel data regression is usually used to make observations of data that is examined continuously for several periods. The purpose of this study is to determine the factors that influence the level of poverty in Madura Island in the period 2008 - 2017. In this study the variables used in this study are life expectancy $\left(X_{1}\right)$, average length of school $\left(X_{2}\right)$, level open unemployment $\left(X_{3}\right)$, and labor force participation $\left(X_{4}\right)$ with the Comman Effect Model (CEM) approach, Fixed Effect Model and Random Effect Model (REM). To choose the best model from the three is the chow test, the hausman test and the breusch-pagan test. In this study, the best model chosen was the Fixed Effect Model.
\end{abstract}

Keywords: CEM, Fixed Effect Model, Data Panel Regression, REM, Poverty level.

\section{PENDAHULUAN}

Istilah kemiskinan muncul ketika seseorang atau sekelompok orang tidak mampu mencukupi tingkat kemakmuran ekonomi yang dianggap sebagai kebutuhan minimal dari standar hidup tertentu atau kemiskinan dipahami sebagai keadaan kekurangan uang dan barang untuk menjamin kelangsungan hidup. Kemiskinan adalah suatu konsep menyeluruh (intergrated concept) yang memiliki lima dimensi, yaitu: kemiskinan, ketidakberdayaan, kerentanan menghadapi situasi darurat, ketergantungan, dan keterasingan, baik secara geografis maupun sosiologis (Chambers, 1988).

Pulau Madura merupakan pulau yang memiliki 4 kabupaten dengan persentase tingkat kemiskinan 5 besar tertinggi di Propinsi Jawa Timur. Semakin tinggi jumlah dan persentase penduduk miskin di suatu daerah tentu saja akan menjadi beban pembangunan, sehingga peran pemerintah dalam mengatasinya pun akan semakin besar. Keberadaan jumlah penduduk miskin di Pulau Madura yang masih relatif besar dapat menegaskan bahwa kebijakan dan program pengentasan kemiskinan yang dijalankan oleh pemerintah dalam beberapa tahun terakhir tidak cukup efektif untuk memperbaiki taraf hidup penduduk miskin di Pulau Madura.

Regresi data panel merupakan pengembangan dari analisis regresi yang merupakan gabungan dari data time series dan data cross section. Regresi data panel biasanya digunakan untuk melakukan pengamatan terhadap suatu data yang diteliti secara terus menerus selama beberapa periode. Keuntungan dari analisis regresi data panel adalah mempertimbangkan keragaman yang terjadi dalam unit cross section dan lebih informatif daripada time series sederhana secara keseluruhan.

Menurut penelitian sebelumnya terdapat beberapa faktor yang telah terbukti memberikan pengaruh yang signifikan terhadap tingkat kemiskinan. Seperti penelitian yang dilakukan oleh Rayyan (2018) yaitu "Analisis Regresi Data Panel Pada Faktor - Faktor yang 
Mempengaruhi Tingkat Kemiskinan Provinsi Sulawesi Selatan Tahun 2011 - 2015”, yang menyimpulkan bahwa rata - rata lama sekolah dan laju pertumbuhan penduduk memberikan pengaruh terhadap tingkat kemiskinan di Provinsi Sulawesi Selatan. Penelitian yang dilakukan oleh Anisa, dkk (2012) yaitu "Analisis Data Panel Model Efek Acak pada Data Kemiskinan di Provinsi Sulawesi Selatan", yang menyimpulkan bahwa tingkat pengangguran terbuka dan partisipasi angkatan kerja memiliki pengaruh yang positif terhadap tingkat kemiskinan di Provinsi Sulawesi Selatan.

Metode analisis regresi data panel merupakan metode yang tepat digunakan untuk menganalisis faktor - faktor yang mempengaruhi tingkat kemiskinan di Pulau Madura. Pada penelitian ini, data yang digunakan akan ditabulasikan ke dalam struktur data panel. Data cross section dalam studi kasus ini adalah data 4 kabupaten di Pulau Madura. Sedangkan data time series-nya adalah data antar waktu yaitu data yang dikaji dalam periode 2008 2017.

\section{TINJAUAN PUSTAKA}

\subsection{Regresi Data Panel}

Data deret waktu (time series) adalah data satu objek yang meliputi beberapa periode waktu. Data cross section adalah data yang terdiri dari beberapa atau banyak objek dalam suatu periode waktu. Penggabungan data time series dengan cross section disebut dengan data panel. Dengan kata lain, data panel adalah data yang diperoleh dari data cross section yang diobservasi berulang pada unit individu (objek) yang sama pada waktu yang berbeda (Gujarati, 2003). Model regresi data panel.

$$
Y_{i t}=\beta_{0 i t}+\sum_{k=1}^{K} \beta_{k i t} X_{k i t}+\varepsilon_{i}
$$

dengan,

$Y_{i t} \quad=$ variabel dependen (nilai yang diprediksikan) unit cross section ke- $i$ untuk periode ke- $t$

$X_{k i t}=$ variabel independen ke- $k$ untuk unit cross section ke- $i$ periode ke- $t$

$\beta_{0} \quad=$ konstanta slope

$\varepsilon_{i t} \quad=$ error untuk unit cross section ke- $i$ pada periode ke- $t$

$\mathrm{k} \quad=$ banyak parameter regresi yang akan ditaksir

\subsection{Pemilihan Model Estimasi Regresi Data Panel}

a. Uji Chow

Uji Chow digunakan untuk memilih antara Fixed Effect Model atau Common Effect Model yang sebaiknya dipakai. Prosedur pengujian uji Chow adalah sebagai berikut (Baltagi, 2005). Hipotesis yang digunakan adalah

$\mathrm{H}_{0}: \alpha_{1}=\alpha_{2}=\cdots=\alpha_{n}=0$ (Common Effect Model $)$

$\mathrm{H}_{1}$ : minimal ada satu $\alpha_{i} \neq 0 ; i=1,2, \ldots, n$ (Fixed Effect Model)

Statistik uji yang digunakan merupakan uji $\mathrm{F}$, yaitu:

$$
F_{\text {hitung }}=\frac{\left(R S S_{1}-R S S_{2}\right) /(N-1)}{R S S_{2} /(N T-N-K)}
$$

dengan:

$N \quad$ : jumlah individu (data cross section)

$T \quad$ : jumlah periode waktu (data time series)

$K \quad$ : jumlah variabel penjelas

$R S S_{1} \quad$ : residual sum of squares hasil pendugaan Common Effect Model

$R S_{2}$ : residual sum of squares hasil pendugaan Fixed Effect Model 


\section{b. Uji Hausman}

Uji ini menguji apakah terdapat hubungan antara galat pada model (galat komposit) dengan satu atau lebih variabel penjelas dalam model. Prosedur pengujian uji Hausman adalah sebagai berikut (Baltagi, 2005). Hipotesis yang digunakan adalah sebagai berikut.

$\mathrm{H}_{0}:$ Korelasi $\left(X_{i t}, \varepsilon_{i t}\right)=0$ (Random Effect Model)

$\mathrm{H}_{1}$ : Korelasi $\left(X_{i t}, \varepsilon_{i t}\right) \neq 0$ (Fixed Effect Model)

Statistik uji yang digunakan adalah uji Chi-Square berdasarkan kriteria Wald, yaitu:

dengan:

$$
\mathrm{W}=\left(\hat{\beta}_{M E T}-\hat{\beta}_{M E A}\right)^{\prime}\left[\operatorname{var}\left(\hat{\beta}_{M E T}-\hat{\beta}_{M E A}\right)\right]^{-1}\left(\hat{\beta}_{M E T}-\hat{\beta}_{M E A}\right)
$$

$\hat{\beta}_{M E T}$ : vektor estimasi kemiringan Fixed Effect Model

$\hat{\beta}_{M E A}$ : vektor estimasi kemiringan Random Effect Model

\section{c. Uji Breusch-Pagan}

Uji ini Menurut Rosadi (2011) uji Breusch-Pagan digunakan untuk menguji adanya efek waktu, individu atau keduanya dengan hipotesis sebagai berikut. Hipotesis uji BreuschPagan adalah sebagai berikut.

$\mathrm{H}_{0}: \sigma_{e}^{2}=0$ (Common Effect Model)

$\mathrm{H}_{1}$ minimal ada $\sigma_{e}^{2} \neq 0$ (Random Effect Model)

dengan:

$$
L M=\frac{N T}{2(T-1)}\left[\frac{\sum_{i=1}^{N}[T \bar{e}]^{2}}{\sum_{i=1}^{N} \sum_{t=1}^{T} e_{i t}^{2}}-1\right]^{2}
$$

$$
\begin{array}{ll}
T & \text { : jumlah unit time series } \\
N & \text { : jumlah unit cross section } \\
e_{i t} & \text { : residual pada unit ke ke- } i \text { dan waktu ke- } t
\end{array}
$$

\subsection{Pengujian Parameter}

\section{a. Uji Serentak (F)}

Untuk mengetahui apakah model fixed effect pada data panel signifikan maka dilakukan uji hipotesis menggunakan uji $\mathrm{F}$ dengan mengasumsikan bahwa gangguan $\varepsilon_{i}$ didistribusikan secara normal. Statistik uji yang digunakan untuk model dengan efek individu sama dengan untuk model dengan efek waktu.

$$
\mathrm{F}_{\text {hitung }}=\frac{\left(S S E_{P}-S S E_{D V}\right) /(N-1)}{\left(S S E_{D V}\right) /(N T-N-1)}
$$

\section{b. Uji Parsial (T)}

Untuk menguji hipotesis bahwa variabel bebas $X_{\mathrm{j}}$ tidak mempengaruhi variabel terikat $Y$ (dengan asumsi variabel bebas lainnya konstan), berarti $\beta_{\mathrm{j}}=0$. Maka perumusannya adalah sebagai berikut:

$$
\begin{aligned}
& \mathrm{H}_{0}: \beta_{j}=0 \\
& \mathrm{H}_{1}: \beta_{j} \neq 0, j=0,1,2, \ldots, k(k \text { adalah koefisien slope })
\end{aligned}
$$

di dalam pengujian hipotesis tentang koefisien regresi parsial $\left(\beta_{\mathrm{j}}\right)$, digunakan statistik uji $\mathrm{t}$ sebagai berikut:

$$
t=\frac{\widehat{\beta}_{j}-\beta_{j}}{\operatorname{se}\left(\widehat{\beta}_{j}\right)}
$$

karena $\beta_{\mathrm{j}}$ akan diuji apakah sama dengan $0\left(H_{0}: \beta_{\mathrm{j}}=0\right)$, maka nilai $\beta_{\mathrm{j}}$ dalam persamaan diganti dengan nol sehingga persamaan uji t menjadi:

$$
t=\frac{\widehat{\beta}_{j}}{\operatorname{se}\left(\widehat{\beta}_{j}\right)}
$$


persamaan (7) mengikuti distribusi t dengan derajat kebebasan sebesar $(n-k)$.

\section{METODE PENELITIAN}

\subsection{Sumber Data dan Variabel}

Data yang digunakan dalam penelitian ini adalah data sekunder yang diperoleh dari Badan Pusat Statistik Jawa Timur terkait data persentase kemiskinan pada kabupaten di Pulau Madura. Data sekunder yang digunakan merupakan data pada tahun 2008 - 2017 dengan unit observasi sebanyak 4 kabupaten di Pulau Madura, yaitu kabupaten Bangkalan, kabupaten Sampang, kabupaten Pamekasan dan kabupaten Sumenep.

Tabel 1. Variabel Penelitian Data Panel

\begin{tabular}{cll}
\hline Variabel & \multicolumn{1}{c}{ Indikator } & Skala \\
\hline Dependen & Tingkat kemiskinan & Rasio \\
\hline \multirow{3}{*}{ Independen } & Angka harapan hidup & Rasio \\
\cline { 2 - 3 } & Rata-rata lama sekolah & Rasio \\
\cline { 2 - 3 } & Tingkat pengangguran terbuka & Rasio \\
\cline { 2 - 3 } & Partisipasi angkatan kerja & Rasio \\
\hline
\end{tabular}

\subsection{Metode Analisis Data}

Metode analisis data yang dilakukan dalam menghasilkan analisis untuk data panel dapat dituliskan sebagai berikut.

1. Mengambil data faktor - faktor yang diduga mempengaruhi tingkat kemiskinan pada 4 Kabupaten di Pulau Madura di Badan Pusat Statistik Provinsi Jawa Timur periode 2008 - 2017. Khusus untuk variabel Tingkat Pengangguran Terbuka $\left(\mathrm{X}_{3}\right)$ dan Partisipasi Angkatan Kerja $\left(\mathrm{X}_{4}\right)$ tahun 2016 tidak tersedia di BPS. Maka dalam penelitian ini dilakukan mean substitution (Buuren, 2012), untuk menggantikan data yang missing dengan rata - rata data variabel $\mathrm{X}_{3}$ dan $\mathrm{X}_{4}$ dari tahun 2008 2015.

2. Menentukan variabel - variabel dalam penelitian ini.

3. Melakukan analisis deskriptif terkait variabel penelitian.

4. Melakukan pengujian regresi data panel dengan menggunakan Uji Chow, Uji Hausman, dan Uji Breusch-Pagan.

5. Mengestimasi parameter model regresi data panel yang terpilih.

6. Melakukan Uji asumsi model regresi data panel.

a. Uji normalitas

b. Uji multikolinearitas

c. Uji heteroskedastisitas

d. Uji autokorelasi

7. Menarik kesimpulan dari model regresi data panel untuk faktor - faktor yang berpengaruh terhadap tingkat kemiskinan di Pulau Madura berdasarkan hasil yang diperoleh dari analisis regresi data panel

\section{HASIL DAN PEMBAHASAN}

Analisis untuk mendapatkan faktor yang mempengaruhi tingkat kemiskinan di pulau Madura diawali dengan melakukan analisis deskriptif, pengujian regresi data panel yaitu 
dengan uji chow, uji hausman, uji breushch-pagan, pemodelan dengan efek cross section dan time series, serta pengujian asumsi IIDN. Berikut adalah Hasil analisis statistika deskriptif yang disajikan pada Tabel 1.

Tabel 1. Statistika Deskriptif Data Tingkat Kemiskinan di Madura

\begin{tabular}{lrrrrr}
\hline & Kemiskinan & \multicolumn{1}{c}{ AHH } & RLS & TPT & PAK \\
\hline Mean & 24.1 & 66.98 & 4.73 & 3.32 & 72.79 \\
\hline Median & 23.39 & 67.42 & 4.95 & 2.54 & 73.65 \\
\hline Minimum & 16 & 61.69 & 3.14 & 1.01 & 65.86 \\
\hline Maximum & 34.53 & 70.71 & 6.25 & 7.26 & 78.76 \\
\hline Std. Dev & 4.68 & 2.72 & 0.83 & 1.66 & 3.41 \\
\hline
\end{tabular}

Hasil statistik deskriptif ditinjau dari nilai standar deviasi, variabel Tingkat Kemiskinan mempunyai nilai standar deviasi terbesar yaitu 4.68 dibandingkan dengan variabel yang lain. Standar deviasi merupakan cerminan dari rata - rata penyimpangan data dari mean

\subsection{Pengujian Regresi Data Panel}

\section{a. Uji Chow}

Langkah pertama untuk menentukan model terbaik regresi data panel yaitu dengan melakukan uji chow. Uji chow digunaka untuk memilih model antara Common Effect Model dan Fixed Effect Model. Hasil pengujian dapat dilihat pada Tabel 2.

\begin{tabular}{cc}
\multicolumn{2}{c}{ Tabel 2. Hasil Uji Chow } \\
\hline F $_{\text {hitung }}$ & P-value \\
\hline 27.3149 & 5.931e-09
\end{tabular}

Dari hasil pengujian pada Tabel 2 terlihat nilai $F_{\text {hitung }}$ sebesar 27.3149, dengan $\mathrm{df}_{1}$ (3) dan $\mathrm{df}_{2}$ (32) diperoleh nilai $\mathrm{F}_{\text {tabel }}$ sebesar 2.20, artinya model yang terpilih adalah Fixed Effect Model.

\section{b. Uji Hausman}

Uji Hausman digunakan untuk memilih antara Fixed Effect Model atau Random Effect Model yang sebaiknya dipakai. Berikut adalah hipotesis yang digunakan dalam pengujian ini. Apabila nilai $p$-value $<\alpha(5 \%)$ maka tolak $\mathrm{H}_{0}$ sehingga model yang terpilih adalah Fixed Effect Model.

Tabel 3. Hasil Uji Hausman

\begin{tabular}{ccc}
\hline & Chi-square & $P$-value \\
\hline Hausman Test & 33.7704 & $8.305 \mathrm{e}-7$ \\
\hline
\end{tabular}

Berdasarkan hasil uji hausman pada Tabel 3 diperoleh nilai chi-square sebesar 33.7704, dengan $\alpha(0.05)$ nilai $X^{2}$ Tabel $=9.48773$. maka $X^{2}$ hitung $>X^{2}$ Tabel artinya $\mathrm{H}_{0}$ ditolak. Maka dapat disimpulkan bahwa model terbaik yang dipilih menggunakan uji hausman yaitu Fixed Effect Model.

\section{c. Uji Breusch-Pagan}

Uji Breusch-Pagan digunakan untuk memilih antara Common Effect Model atau Random Effect Model yang sebaiknya dipakai. Berikut adalah hasil uji breusch-pagan pada Tabel 4 


\begin{tabular}{cl}
\hline LM & P-value \\
\hline 11.55 & 0.003105 \\
\hline
\end{tabular}

Tabel 4 diperoleh nilai lagrange multiplier sebesar 11.55, dengan $\alpha(5 \%)$ nilai $X^{2}$ Tabel $=$ 3.84146. maka $>X^{2}$ Tabel artinya $\mathrm{H}_{0}$ ditolak. Maka dapat disimpulkan bahwa model terbaik yang dipilih menggunakan uji hausman yaitu Random Effect Model.

\subsection{Model Regresi Data Panel}

\section{a. Efek Cross Section}

Pada model efek cross section, yang diperhitungkan adalah pengaruh unit - unit cross section atau cross section yaitu 4 Kabupaten di Pulau Madura terhadap Tingkat Kemiskinan dengan melibatkan 4 variabel dummy yang mewakili 4 Kabupaten tersebut. Hasil pengujian Regresi Data Panel untuk model efek cross section dapat dilihat pada Tabel 5.

Tabel 5 Estimasi Koefisien Model Efek Cross section

\begin{tabular}{cccc}
\hline Variabel & Estimasi & Variabel & Estimasi \\
\hline $\mathrm{X}_{1}$ & -1.24026 & $\mathrm{D}_{1}$ & 85.466 \\
\hline $\mathrm{X}_{2}$ & -0.31349 & $\mathrm{D}_{2}$ & 77.332 \\
\hline $\mathrm{X}_{3}$ & 0.54124 & $\mathrm{D}_{3}$ & 86.239 \\
\hline $\mathrm{X}_{4}$ & 0.32463 & $\mathrm{D}_{4}$ & 83.922 \\
\hline
\end{tabular}

Tabel 5 diatas, model regresi data panel untuk Fixed Effect Model (cross section) dapat diduga dengan persamaan sebagai berikut.

$$
\begin{aligned}
\hat{Y}= & 85.466 D_{1}+77.332 D_{2}+86.239 D_{3}+83.922 D_{4}-1.24026 X_{1}-0.31349 X_{2}+ \\
& 0.54124 X_{3}+0.32463 X_{4}
\end{aligned}
$$

\section{b. Efek Time Series}

Pada model efek time series, yang diperhitungkan adalah pengaruh unit - unit time series dalam hal ini pengaruh rentang time series dari 2008 - 2017 terhadap Tingkat Kemiskinan dengan melibatkan 10 variabel dummy yang mewakili unit time series Hasil pengujian Regresi Data Panel untuk model efek time series dapat dilihat pada tabel berikut.

Tabel 6 Estimasi Koefisien Model Efek Time series

\begin{tabular}{cccccr}
\hline Variabel & Estimasi & Variabel & Estimasi & Variabel & Estimasi \\
\hline $\mathrm{X}_{1}$ & -0.13031 & $\mathrm{P}_{1}$ & 109.958 & $\mathrm{P}_{6}$ & 102.639 \\
\hline $\mathrm{X}_{2}$ & -2.65443 & $\mathrm{P}_{2}$ & 107.176 & $\mathrm{P}_{7}$ & 100.972 \\
\hline $\mathrm{X}_{3}$ & -0.71667 & $\mathrm{P}_{3}$ & 103.162 & $\mathrm{P}_{8}$ & 98.274 \\
\hline $\mathrm{X}_{4}$ & -0.75585 & $\mathrm{P}_{4}$ & 103.723 & $\mathrm{P}_{9}$ & 100.469 \\
\hline & & $\mathrm{P}_{5}$ & 103.181 & $\mathrm{P}_{10}$ & 98.298 \\
\hline
\end{tabular}

Tabel 6 diatas, model regresi data panel untuk Fixed Effect Model (time series) dapat diduga dengan persamaan sebagai berikut.

$$
\begin{aligned}
\hat{Y}= & 109.958 P_{1}+107.176 P_{2}+103.162 P_{3}+103.723 P_{4}+103.181 P_{5}+102.639 P_{6}+ \\
& 100.972 P_{7}+98.274 P_{8}+100.469 P_{9}+98.298 P_{10}-0.13031 X_{1}-2.65443 X_{2}- \\
& 0.71667 X_{3}-0.75585 X_{4}
\end{aligned}
$$




\subsection{Pengujian Regresi Data Panel}

Pengujian ini dilakukan dengan uji $\mathrm{F}$ atau serentak dan uji individu atau uji t pada data tingkat kemiskinan di pulau Madura.

\section{a. Uji F}

Berdasarkan hasil pengujian serentak pada Tabel 7, diperoleh nilai $F_{\text {hitung }}$ sebesar 40.1339, dengan $\alpha(5 \%), \mathrm{k}=4$ dan $\mathrm{n}=40$ maka nilai $\mathrm{F}_{\text {tabel }}$ adalah 2.60. Dengan hasil yang sudh diketahui, terlihat bahwa $F_{\text {hitung }}>\mathrm{F}_{\text {tabel, }}$ maka tidak ada alasan untuk menolak $\mathrm{H}_{0}$. Artinya variabel Angka Harapan Hidup, Rata Lama Sekolah, Tingkat Pengangguran Terbuka dan Partisipasi Angkatan Kerja berpengaruh secara signifikan terhadap Tingkat Kemiskinan baik dari efek cross section maupun time series.

Tabel 7. Hasil Uji F Model Efek Cross Section dan Time Series

\begin{tabular}{lcl}
\hline \multicolumn{1}{c}{ Model } & F & $\boldsymbol{P}$-Value \\
\hline Efek Cross Section & 40,1339 & $4,8617 \mathrm{e}-12$ \\
\hline Efek Time Series & 17,7426 & $3,8915 \mathrm{e}-07$ \\
\hline
\end{tabular}

\section{b. Uji T}

Berdasarkan Tabel 8 terkait hasil pengujian parsial pada Fixed Effect Model pada variabel Angka Harapan Hidup $\left(\mathrm{X}_{1}\right)$, Rata Lama Sekolaah $\left(\mathrm{X}_{2}\right)$, dan Partisipasi Angkatan Kerja $\left(\mathrm{X}_{4}\right)$ diperoleh thitung dan $p$-value kurang dari $\alpha(5 \%)$. Artinya ketiga variabel tersebut berpengaruh signifikan terhadap Tingkat Kemiskinan. Sedangkan variabel Tingkat Pengangguran Terbuka $\left(\mathrm{X}_{3}\right)$ diperoleh $\mathrm{t}_{\text {hitung }}$ sebesar - 1.7556 dan $p$-value 0.090939 lebih dari $\alpha(5 \%)$. Variabel Tingkat Pengangguran Terbuka tidak berpengaruh signifikan terhadap variabel Tingkat Kemiskinan.

Tabel 8. Hasil Uji t dengan efek cross section dan Time Series

\begin{tabular}{cccccc}
\hline \multicolumn{3}{c}{ Efek Cross Section } & \multicolumn{3}{c}{ Efek Time Series } \\
\hline Variabel & $\mathbf{t}$ & $\boldsymbol{P}$-Value & Variabel & $\mathbf{t}$ & $\boldsymbol{P}$-Value \\
\hline $\mathrm{X}_{1}$ & -11.9007 & $2.73 \mathrm{E}-13$ & $\mathrm{X}_{1}$ & -0.5228 & 0.605564 \\
\hline $\mathrm{X}_{2}$ & -0.6689 & 0.50838 & $\mathrm{X}_{2}$ & -5.9178 & $3.04 \mathrm{E}-06$ \\
\hline $\mathrm{X}_{3}$ & 1.5874 & 0.12226 & $\mathrm{X}_{3}$ & -1.7556 & 0.090939 \\
\hline $\mathrm{X}_{4}$ & 2.6111 & 0.01362 & $\mathrm{X}_{4}$ & -3.5274 & 0.001582 \\
\hline
\end{tabular}

Pada pengujian asumsi untuk model regresi data panel diperoleh hasil memenuhi asumsi IIND. Sedangkan pada perbandingan nilai koefisien deterrminasi dari kedua efek diperoleh hasil bahwa koefisien determinasi untuk model dengan efek cross section lebih baik dibandingkan dengan model efek time series yaitu 83,38\% dan 73,19\%.

\subsection{Interpretasi Model}

Dalam Fixed Effect Model terdapat dua model efek yaitu efek cross section dan efek time series. Dari dua pendekatan tersebut dipilih nilai $R^{2}$ yang tertinggi untuk dijadikan model terbaik. Dalam penelitian ini, model terbaik yang dipilih untuk menjelaskan pengaruh variabel Angka Harapan Hidup $\left(\mathrm{X}_{1}\right)$, Rata Lama Sekolah $\left(\mathrm{X}_{2}\right)$, Tingkat Pengangguran Terbuka $\left(\mathrm{X}_{3}\right)$ dan Partisipasi Angkatan Kerja $\left(\mathrm{X}_{4}\right)$ terhadap tingkat kemiskinan adalah Fixed Effect Model dengan efek cross section, model regresi efek cross section dengan 4 Kabupaten seperti pada persamaan (8). 
Pada Tabel 5 terkait Fixed Effect Model diketahui bahwa variabel yang berpengaruh signifikan adalah Angka Harapan Hidup ( $\left.\mathrm{X}_{1}\right)$, Partisipasi Angkatan Kerja $\left(\mathrm{X}_{4}\right)$ dan 4 variabel dummy cross section (Bangkalan, Pamekasan, Sampang, dan Sumenep) terhadap Tingkat Kemiskinan dengan nilai $\mathrm{R}^{2}$ sebesar 0.8338. Yang berarti variabel Angka Harapan Hidup $\left(\mathrm{X}_{1}\right)$, Partisipasi Angkatan Kerja $\left(\mathrm{X}_{4}\right)$ dan 4 variabel dummy cross section (Bangkalan, Pamekasan, Sampang, dan Sumenep) mampu menjelaskan variabel Tingkat Kemiskinan sebesar $83.38 \%$.

Model yang terpilih, terlihat nilai intersep tertinggi berada pada Sampang $\left(D_{3}\right)$, Bangkalan $\left(D_{1}\right)$ dan Sumenep $\left(D_{4}\right)$. Yang berarti Tingkat Kemiskinan pada ketiga Kabupaten di Pulau Madura ini memiliki rata - rata tertinggi. Dapat dilihat pada Lampiran A, bahwa Kabupaten Sampang merupakan Kabupaten dengan Tingkat Kemiskinan tertinggi di Pulau Madura. Dari kurun waktu selama 10 tahun (2008 - 2017) Kabupaten Sampang menenmpati urutan pertama terkait Tingkat Kemiskinan tertinggi di Pulau Madura. Sedangkan untuk Bangkalan dan Sumenep berada pada urutan kedua/ketiga dari tahun 2008 samapai tahun 2017. Nilai intersep terendah terlihat berada pada Pamekasan $\left(D_{2}\right)$ dengan nilai intersep sebesar 77.332. Artinya, Kabupten Pamekasan merupakan Kabupaten dengan Tingkat Kemiskinan terendah di Pulau Madura dari tahun 2008 sampai tahun 2010.

Model yang terpilih, variabel Angka Harapan Hidup memiliki korelasi negatif dan berpengaruh secara signifikan terhadap Tingkat Kemiskinan. Setiap kenaikan Angka Harapan Hidup sebesar 1\% mampu menurunkan Tingkat Kemiskinan sebesar $1.24026 \%$ dengan asumsi bebas variabel lainnya bernilai konstan.

Variabel Partisipasi Angkatan Kerja memiliki korelasi positif dan berpengaruh secara signifikan terhadap Tingkat Kemiskinan. Setiap kenaikan 1\% mampu meningkatkan $0.32463 \%$ Tingkat Kemiskinan. Karena semakin tinggi Partisipasi Angkatan Kerja dapat memicu bertambahnya pengangguran dengan kata lain Tingkat Kemiskinan akan semakin tinggi

\section{KESIMPULAN}

Kesimpulan dari hasil analisa sebagai berikut.

1. Tingkat Kemiskinan (Y) di Pulau Madura dalam kurun waktu 10 tahun (2008 - 2017) mengalami penurunan. Tingkat Kemiskinan pada tahun 2008 adalah Tingkat Kemiskinan tertinggi dengan rata - rata sebesar 30.75 dan pada tahun 2017 Tingkat Kemiskinan terendah dengan rata - rata sebesar 20.13. Wilayah yang dari tahun - tahun tersebut berada pada Tingkat Kemiskinan tertinggi adalah Kabupaten Sampang, sedangkan untuk wilayah yang memiliki Tingkat Kemiskinan terendah adalah Kabupaten Pamekasan.

2. Pemilihan model terbaik yang telah dilakukan, diperoleh model terbaik yaitu model Fixed Effect Model efek cross section dengan $R^{2}$ sebesar $83.38 \%$. Model efek cross section dengan 4 Kabupaten seperti yang tertulis pada persamaan 9. Dari model terpilih dapat dilihat terdapat beberapa variabel independen yang signifikan yaitu Angka Harapan Hidup $\left(\mathrm{X}_{1}\right)$, Partisipasi Angkatan Kerja $\left(\mathrm{X}_{4}\right)$ dan variabel dummy dari efek cross section.

\section{DAFTAR PUSTAKA}

Anisa, Ilyas, N., Hadijah, (2012), Analisis Data Panel Model Acak pada Data Kemiskinan di Provinsi Sulawesi Selatan, Jurnal Matematika, Statistika, dan Komputasi, Vol. 8 No. 2, Universitas Hasanuddin, Makassar. 
Baltagi, Bani H, 2005, Econometric Analysis of Panel Data 3rd Ed, West Sussex: John Wiley and Sons Ltd.

Badan Pusat Statistik, 2011, Profil Pendidikan Sulawesi Selatan Tahun 2011, Makassar: Badan Pusat Statistik Provinsi Sulawesi Selatan.

Badan Pusat Statistik, 2015, Perhitungan dan Analisis Kemiskinan Makro Indonesia Tahun 2015, Jakarta: Badan Pusat Statistik.

Badan Pusat Statistik, 2017, Indikator Kesejahteraan Rakyat Provinsi Jawa Timur Tahun 2016, Surabaya: Badan Pusat Statistik Provinsi Jawa Timur.

Chambers, Robert, 1983, Rural Development, Putting The Last First. London: Longman.

Ismi R,, (2018), Analisis Regresi Data Panel Pada Faktor - Faktor Yang Mempengaruhi Tingkat Kemiskinan Provinsi Sulawesi Selatan Tahun 2011 - 2015 [Skripsi], Makassar: Program Sarjana Jurusan Matematika Fakultas Sains dan Teknologi, Universitas Islam Negeri Alauddin Makassar,

Gujarati, Damodar, 2003, Basic Econometrics $4^{\text {th }}$ Edition, New York: McGraw - Hill. 